\title{
Reply to letter to the editor about radiotherapy in the management of heel spur pain
}

\author{
Bora Uysal ${ }^{1}$ (])
}

Received: 9 November 2017 / Accepted: 13 December 2017 / Published online: 19 December 2017

๑) Springer-Verlag France SAS, part of Springer Nature 2017

\section{Dear Editor,}

I have read the letter to the editor by Pinar Doruk Analan in your publication volume 27 issue 4 . Radiation oncologists are better known with their pioneer success in the management of heel spur pain. We would like to reply this letter to the editor step by step.

1. Social security system of Turkey pays all the costs of $\mathrm{X}$-ray and radiotherapy for the patients in the social system. The term referred to our department means that patients diagnosed with heel spur are consulated from policlinic of Orthopedics or Physical Medicine and Rehabilitation (PMR). We did not enroll any other clinicians from PMR or Orthopedics to our article because of the fact that no other clinic is capable of applying radiotherapy for heel spur pain. We selected the patients with heel spur from our clinical database.

2. We got informed consents from all patients before the treatment in the guidance of Declaration of Helsinki. We recommend the author to read this declaration.
3. We selected inclusion criteria according to the similar studies. The author wrote insufficient criteria; however, she did not mention why she thought like that. The patients were examined and diagnosed as calcaneal spur according to the X-ray film. We use 2D X-ray before the planning. Shortly after that, we settle the radiotherapy portal with this image which was mentioned in our study.

4. We suggest author to read references of 13th and 15th. Ulutin et al. mentioned that no adverse effects were seen after heel spur radiotherapy. Heyd et al. evaluated that no carcinogenic effect was seen after these doses. We did not experience any adverse effect or secondary cancer in the calcaneal radiotherapy area since 1990's.

\section{Compliance with ethical standards}

Conflict of interest The author declares that he has no competing interests.
Bora Uysal

drborauysal@windowslive.com

1 Department of Radiation Oncology, Gulhane Training and Research Hospital, 06018 Etlik, Kecioren, Ankara, Turkey 